\title{
Utilização do Farelo de Germe de Milho Desengordurado na Alimentação de Suínos em Crescimento e Terminação - Digestibilidade e Desempenho ${ }^{1}$
}

\author{
Ivan Moreira ${ }^{2}$, Cleber Rogério Ribeiro ${ }^{3}$, Antonio Cláudio Furlan², Cláudio Scapinello², \\ Marianne Kutschenko ${ }^{3}$
}

\begin{abstract}
RESUMO - Foram conduzidos dois experimentos (Digestibilidade e Desempenho), objetivando avaliar o valor nutricional e a viabilidade de utilização do farelo de germe de milho desengordurado (FGMD) em rações de suínos, na fase de crescimento e terminação.

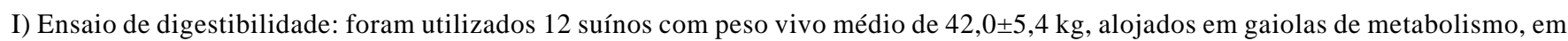
que seis receberam rações compostas de 70\% de ração referência e 30\% de FGMD e seis receberam ração referência. O FGMD apresentou coeficiente de digestibilidade da energia de $80,98 \%$ e coeficiente de metabolização de 78,04\%, o que corresponde a $3.060 \mathrm{kcal}$ de ED/kg e $2.949 \mathrm{kcal}$ de EM/kg. II) Ensaio de desempenho: foram utilizados 32 suínos mestiços, sendo metade de fêmeas e metade de machos castrados, com peso inicial médio de $31,9 \pm 3,6 \mathrm{~kg}$. Os suínos foram alojados em 16 baias, perfazendo, assim, 2 animais por baia. Os animais receberam ração à vontade, contendo níveis crescentes $(0,15,30$ e 45\%) de farelo de germe de milho desengordurado. Foi utilizado o delineamento em blocos casualizados, com quatro tratamentos, quatro repetições, com dois animais por unidade experimental. A inclusão de níveis crescentes de FGMD prejudicou o desempenho dos suínos, reduziu a espessura de toucinho e não influenciou a profundidade do lombo, medidas no animal vivo. A análise econômica, considerando o preço do FGMD, sendo $80 \%$ do preço do milho, mostrou que o nível de $15 \%$ de inclusão do FGMD é o mais econômico, tanto para a fase de crescimento, quanto para a fase de terminação.
\end{abstract}

Palavras-chave: características de carcaça, desempenho, digestibilidade, processamento, subproduto

\section{Utilization of Defatted Corn Germ Meal on Growing-Finishing Pigs Feeding - Digestibility and Performance}

\begin{abstract}
Two studies (Digestibility and Performance) were carried out to evaluate the nutritional value and the feasibility of using defatted corn germ meal (DCGM) fed to growing-finishing pigs. I) Digestibility trial: Twelve pigs with initial body weight of $42.0 \pm 5.4 \mathrm{~kg}$ were hold in metabolism cage. Six pigs were fed a diet with $70 \%$ of basal diet plus $30 \%$ of DCGM and six received basal diet. DCGM showed an energy digestibility coefficient of $80.98 \%$ and metabolisation coefficient of $78.04 \%$, that means $3,060 \mathrm{kcal}$ of $\mathrm{DE} / \mathrm{kg}$ and 2,949 Kcal of ME/kg. II) Performance trial: A total of 32 crossbreed swine were used, half castrated males and half females, with an initial body weigh of $31.9 \pm 3.6 \mathrm{~kg}$. Pigs were placed on 16 pens with two animals per pen. The animals were fed a ration containing increasing levels $(0,15,30$ e $45 \%)$ of defatted corn germ meal. It was used a randomized complete block design, with four treatments and four replicates with two animals per experimental unit. Increasing levels of DCGM impaired swine performance decreased backfat thickness and did not affected loin depth, measured on animal alive. Economical study, considering DCGM price as $80 \%$ of corn price, showed that $15 \%$ level of DCGM is the most profitable, either on growing or finishing phase.
\end{abstract}

Key Words: byproduct, carcass traits, digestibility, performance, processing

\section{Introdução}

Na suinocultura brasileira, os gastos com alimentação representam cerca de $70 \%$ dos custos médios de produção de suínos para abate (Girotto \& Santos Filho, 2000). Face a isso, o sucesso financeiro de qualquer granja está, diretamente, relacionado com os preços dos ingredientes das rações. Considerando-se que as rações são constituídas, basicamente, por milho e farelo de soja, que apresentam constante quadro de instabilidade de preços, é clara a necessidade da procura de novas alternativas que possam substituir economicamente esses ingredientes.

Segundo Patience et al. (1995), os suínos alimentados com rações à base de milho possuem diferenças quanto à gordura da carcaça, em comparação aos suínos alimentados com trigo ou cevada, pois o milho contém, aproximadamente, $3,5 \%$ de gordura, sendo este valor alto, se comparado com o de $1,7 \%$ de gordura do trigo e da cevada.

\footnotetext{
1 Parte do trabalho de Graduação do segundo autor, parcialmente financiado pela Kowalsky Alimentos Ltda.

2 Professores do DZO/UEM. E.mail: imoreira@uem.br; acfurlan@uem.br; cscapinello@uem.br

${ }^{3}$ Alunos do curso de Zootecnia, bolsistas de Iniciação Científica, respectivamente, de IC/CNPq e PIBIB/CNPq. Endereço: Universidade Estadual de Maringá. Av. Colombo, 5790, CEP: 87.020-900 - Maringá - PR.
} 
Dentre os ingredientes não convencionais, podese destacar o farelo de germe de milho desengordurado como uma opção para substituir o milho. Este alimento é um subproduto da industrialização do milho para retirada do amido por via úmida. Durante o processo, o milho é umedecido para amaciar a semente e facilitar a separação do glúten, proteína e germe. Após a remoção do germe de milho, restam apenas o glúten, o amido e a casca do milho (Patience et al., 1995).

Aproximadamente, 25\% da composição do germe de milho é óleo (Ohiocorn, 2000b). O farelo de germe de milho desengordurado é obtido da extração do óleo dos gérmens do milho os quais, depois de retirados da semente na moagem úmida, são secados e prensados (Andriguetto et al., 1982).

Segundo Honeyman (1989), citado por Trindade Neto et al. (1995), para cada $100 \mathrm{~kg}$ de milho em grãos, são produzidos 62 a $68 \mathrm{~kg}$ de amido, $3 \mathrm{~kg}$ de óleo, 3,2 kg de farelo de germe, $20 \mathrm{~kg}$ de glúten e $4,5 \mathrm{~kg}$ de farelo de glúten.

Lassiter \& Edwards (1982) informam que os farelos de germe de milho e de glúten, possuem baixa palatabilidade e que, embora o germe de milho possua um melhor balanço de aminoácidos (maior quantidade de lisina e triptofano), possui valor limitado na alimentação de não-ruminantes.

Entretanto, Freitas (1998) afirma que o germe de milho apresenta boa palatabilidade. Por ouro lado, Simmons (1979) informa que o germe de milho é facilmente consumido por todos os suínos.

Em função dos altos teores de fibra e gordura, existe restrição a altas inclusões do germe de milho. Além disto, tem sido observado que granjas de suínos que utilizam o gérmen, em combinação com outro ingrediente de menor valor energético, têm seus resultados melhorados, principalmente, em conversão alimentar (Freitas, 1998).

Estas informações sugerem que é possível que a utilização do farelo de germe de milho desengordurado poderá superar estes problemas e propiciar melhor desempenho dos suínos, em relação ao farelo de germe de milho integral.

Em trabalho realizado com farelo de glúten de milho, com suínos em crescimento e terminação, Trindade Neto et al. (1995) observaram efeitos prejudiciais no desempenho dos animais e baixa palatabilidade devidos à acidez e ao sabor amargo adquiridos no processo de industrialização do subproduto.

R. Bras. Zootec., v.31, n.6, p.2238-2246, 2002
Butolo et al. (2000), em trabalho realizado com frangos de corte, determinou valores energéticos do farelo de germe de milho desengordurado. Os valores para energia metabolizável aparente e corrigida são, respectivamente, $2.393 \mathrm{kcal} / \mathrm{kg}$ e $2.310 \mathrm{kcal} / \mathrm{kg}$. Estes resultados mostram que o valor energético do farelo de germe de milho desengordurado, para aves, é cerca de $68 \%$ dos valores energéticos do milho grão. Para suínos, também espera-se que o valor energético seja menor.

Diante deste quadro, devido à disponibilidade do alimento e à falta de pesquisas com o farelo de germe de milho desengordurado, este experimento foi realizado com os objetivos de avaliar a digestibilidade, o desempenho e as características de carcaça de suínos em crescimento e terminação e estudar a viabilidade econômica de sua utilização em rações práticas de suínos.

\section{Material e Métodos}

Foram conduzidos dois experimentos, utilizando o produto comercializado com o nome de "Farelo de gérmen de milho peletizado". O produto utilizado em ambos os experimentos foi recebido ensacado e na forma peletizada, sendo moído na mesma peneira de moagem do milho grão, antes de ser incorporado às rações experimentais.

\section{Experimento 1 (Ensaio de digestibilidade)}

Os animais foram alojados em uma sala de metabolismo e mantidos em gaiolas de digestibilidade semelhantes às descritas por Pekas (1968). Foram utilizados 12 suínos mestiços, todos machos castrados, pesando em média 42,0 $0 \pm 5,36 \mathrm{~kg}$ de peso vivo. Os suínos foram submetidos a um período de sete dias de adaptação às gaiolas e às rações, seguido de cinco dias de coleta de fezes e urina.

A ração referência (RR), à base de milho e farelo de soja (Tabela 1), foi formulada para atender às exigências apresentadas pelo NRC (1998). A ração teste (RT) foi composta por $70 \%$ de RR e $30 \%$ de farelo de germe de milho desengordurado.

As rações foram oferecidas em duas refeições diárias, às 8 e $16 \mathrm{~h}$. A quantidade fornecida diariamente foi estabelecida de acordo com o consumo médio e o peso metabólico $\left(\mathrm{kg}^{0,75}\right)$ dos suínos obtidos durante o período de adaptação. A água foi fornecida no comedouro após as refeições, na proporção de $3,0 \mathrm{~mL} / \mathrm{g}$ de ração.

Foi utilizado o método de coleta total de fezes, 
onde se determinou o início e o fim da coleta, através da adição de marcador $\left(2 \%\right.$ de $\left.\mathrm{Fe}_{3} \mathrm{O}_{2}\right)$ às rações. As fezes foram coletadas, diariamente, às $8 \mathrm{~h}$, em sacos plásticos e armazenados em freezer, até a analise laboratorial.

A urina foi recolhida em baldes plásticos, contendo $20 \mathrm{~mL}$ de $\mathrm{HCl}$ (diluído na proporção 1:1). No funil coletor, foi colocado um pedaço de "tule (filó)", objetivando reter as impurezas. A coleta foi feita diariamente às $8 \mathrm{~h} 30$ e o volume foi completado com água destilada para um valor constante para todos os

Tabela 1 - Composição percentual, composição química e valor energético da ração referência (matéria natural)

Table 1 - Percentage and chemical composition and energy value of basal diet (dry mater)

\begin{tabular}{lr}
\hline Ingredientes & $\%$ \\
Ingredients & \\
\hline Milho moído (Corn) & 69,60 \\
Farelo de soja (Soybean meal) & 26,24 \\
Fosfato bicálcico (Dicalcium phosphate) & 1,05 \\
Calcário calcítico (Limestone) & 0,85 \\
Sal iodado (Salt) & 0,40 \\
Óleo de soja bruto (Crude soybean oil) & 1,26 \\
Tylan S100 & 0,10 \\
Suplemento vitamínico ${ }^{1}$ (Vitamin premix) & 0,30 \\
Suplemento mineral ${ }^{2}$ (Mineral premix) & 0,20 \\
Valores analisados ${ }^{3}$ (Analyzed values) & \\
Matéria seca (Dry matter), \% & 95,50 \\
Energia bruta (Gross energy), kcal/kg & 3.842 \\
Proteína bruta (Crude protein), \% & 16,67 \\
Cálcio (Calcium), \% & 0,78 \\
Fósforo (Phosphorus), \% & 0,50 \\
&
\end{tabular}

Valores calculados 4

Calculated values

\begin{tabular}{lr}
\hline Energia digestível (Digestible energy), kcal $/ \mathrm{kg}$ & 3.410 \\
Lisina (Lysine), \% & 0,87 \\
Metionina + Cistina (Methionine + Cystine), \% & 0,51
\end{tabular}

${ }^{1}$ Suplemento vitamínico para suínos (Vitamin mix). Quantidade por quilograma do produto (amount/kg): Ác. fólico (Folic acid)167,0 mg, Vit. A2.330.000 UI, BHT 32.700,0 mg, Selênio (Selenium) 66,7 mg, Avoparcin $3.340,0 \mathrm{mg}$, Colina (Choline) $43.300,0 \mathrm{mg}$, Ác. Pantotênico (Pantothenic acid) 2.667,0 mg, Ác. nicotínico (Nicotinic acid) $5.567,0 \mathrm{mg}$, Vit. $\mathrm{B}_{12} 66.700,0 \mathrm{mcg}$, Vit. $\mathrm{B}_{6} 667,0 \mathrm{mg}$, Vit. $B_{2} 1.000,0 \mathrm{mg}$, Vit. $B_{1} 234,0 \mathrm{mg}$, Vit. $K_{3} 667,0 \mathrm{mg}$, Vit. E 5.000,0 UI, Vit. $D_{3} 833.000$ UI, Biotina (Biotin) 25,0 mg.

${ }^{2}$ Suplemento mineral para suínos (Mineral mix). Quantidade por quilograma do produto (amount $/ \mathrm{kg}$ ): Cobalto (Cobalt) $500,0 \mathrm{mg}$, Cobre (Copper) $87.500,0 \mathrm{mg}$, Zinco (Zinc) $50.000,0 \mathrm{mg}$, Ferro (Iron) $50.000,0 \mathrm{mg}$, Manganês (Manganese) $20.000,0 \mathrm{mg}$, lodo (lodine) $750,0 \mathrm{mg}$.

${ }^{3}$ Análises realizadas no laboratório de nutrição animal da UEM/ DZO (Analyses were performed at the Nutrition Lab of UEM/DZO).

${ }^{4}$ Valores calculados com base nas tabelas da EMBRAPA (1991) e na composição percentual da ração referência (Calculated from EMBRAPA, 1991 tables and basal diets composition). animais. Após a homogeneização, foi retirada uma alíquota de $20 \%$, que foi armazenada em frascos de vidro no freezer, até a análise laboratorial.

Para determinação dos coeficientes de digestibilidade, foram obtidos os valores de matéria seca, proteína bruta e energia bruta dos ingredientes, da ração teste, da ração referência e das fezes e, a energia bruta da urina, de acordo com os procedimentos indicados por Silva (1990) e Mara (1992).

Os coeficientes de digestibilidade da matéria seca (CDMS), da proteína bruta (CDPB), da energia bruta (CDEB) e o coeficiente de metabolização da energia bruta (CMEB) do FGMD, foram calculados utilizando-se o método de coleta total. Foi aplicada a fórmula de Matterson et al. (1965) para a obtenção dos valores energéticos do FGMD.

Tabela 2 - Composição química, valor energético e preço de alguns alimentos utilizados nas rações (matéria natural)

Table 2 - Chemical composition, energy values and price of some feedstuffs used in the experimental diets (as fed basis)

\begin{tabular}{|c|c|c|c|}
\hline $\begin{array}{l}\text { Item } \\
\text { Item }\end{array}$ & $\begin{array}{l}\text { FGMD }^{1} \\
D C G M\end{array}$ & $\begin{array}{c}\text { Milho }^{2} \\
\text { Yellow } \\
\text { corn }\end{array}$ & $\begin{array}{c}\text { Farelo de } \\
\text { soja }^{2} \\
\text { Soybean } \\
\text { meal }\end{array}$ \\
\hline $\begin{array}{l}\text { Matéria seca (\%) } \\
\text { Drv matter }\end{array}$ & 91,14 & 89,86 & 88,22 \\
\hline Proteína bruta (\%) & 10,20 & 8,68 & 44,84 \\
\hline $\begin{array}{l}\text { Crude protein } \\
\text { Lisina }(\%)\end{array}$ & 0,28 & 0,24 & 2,65 \\
\hline $\begin{array}{l}\text { Lysine } \\
\text { Cálcio }(\%)\end{array}$ & 0,60 & 0,04 & 0,25 \\
\hline Calcium & & & \\
\hline $\begin{array}{l}\text { Fósforo total (\%) } \\
\text { Total phosphorus }\end{array}$ & 0,41 & 0,26 & 0,60 \\
\hline $\begin{array}{l}\text { Extrato etéreo }(\%) \\
\text { Ether extract }\end{array}$ & 1,27 & 3,84 & 1,74 \\
\hline $\begin{array}{l}\text { Energia bruta }(\mathrm{kcal} / \mathrm{kg}) \\
\text { Gross energy }\end{array}$ & 3.779 & 3.950 & 4.187 \\
\hline $\begin{array}{l}\text { Energia digestível }(\mathrm{kcal} / \mathrm{kg}) \\
\text { Digestible energy }\end{array}$ & $3.060^{3}$ & 3.460 & 3.448 \\
\hline $\begin{array}{l}\text { Preço, } \mathrm{R} \$ / \mathrm{kg}^{4} \\
\text { Price }\end{array}$ & 0,160 & 0,200 & 0,344 \\
\hline
\end{tabular}

${ }^{1}$ Análises realizadas no laboratório de nutrição animal da FUEM/ DZO (Analyses were performed at the Nutrition Lab of FUEM/DZO).

2 Dados baseados nas tabelas da EMBRAPA (1991) (Data based on EMBRAPA [1991\} tables).

3 Valores calculados com base no coeficiente de digestibilidade $(80,98 \%)$, obtido no experimento de digestibilidade, indicado na Tabela 6 e da energia bruta $(3.779 \mathrm{kcal} / \mathrm{kg})$ da amostra utilizada neste experimento de desempenho (Values calculated based on digestible coefficient (80.98\%), from digestibility trial, indicated on Table 6 and crude energy ( $3.779 \mathrm{kcal} / \mathrm{kg}$ ) of performance trial used sample).

4 Preços vigentes em Maringá - PR, em junho/2000 (Current prices in Maringá-PR in June/2000). 
Tabela 3 - Composição centesimal das rações experimentais fornecidas aos suínos, na fase de crescimento e terminação

Table 3 - Percentage composition of experimental diets fed growing-finishing pigs

\begin{tabular}{|c|c|c|c|c|c|c|c|c|}
\hline \multirow{3}{*}{$\begin{array}{l}\text { Itens } \\
\text { Item }\end{array}$} & \multicolumn{8}{|c|}{$\begin{array}{c}\text { Níveis de inclusão de FGMD , \% } \\
\text { DCGM inclusion levels }\end{array}$} \\
\hline & \multicolumn{4}{|c|}{ Crescimento (Growing) } & \multicolumn{4}{|c|}{ Terminação(Finishing) } \\
\hline & 0 & 15 & 30 & 45 & 0 & 15 & 30 & 45 \\
\hline FGMD $(D C G M)$ & - & 15,00 & 30,00 & 45,00 & - & 15,00 & 30,00 & 45,00 \\
\hline Milho (Corn) & 73,36 & 59,20 & 43,86 & 28,53 & 79,31 & 65,28 & 50,23 & 34,86 \\
\hline Farelo de soja (Soybean meal) & 23,90 & 23,22 & 22,74 & 22,28 & 18,52 & 17,81 & 17,28 & 16,83 \\
\hline Óleo de soja (Soybean oil) & - & 0,16 & 1,22 & 2,28 & - & - & 0,83 & 1,90 \\
\hline Fosfato bicálcico (Dicalcium phosphate) & 1,06 & 0,92 & 0,78 & 0,65 & 0,59 & 0,48 & 0,37 & 0,28 \\
\hline Calcário calcítico (Limestone) & 0,68 & 0,52 & 0,40 & 0,26 & 0,72 & 0,57 & 0,43 & 0,27 \\
\hline Sal iodado (Salt) & 0,40 & 0,40 & 0,40 & 0,40 & 0,40 & 0,40 & 0,40 & 0,40 \\
\hline Suplemento vitamínico ${ }^{1}$ (Vitamin mix) & 0,30 & 0,30 & 0,30 & 0,30 & 0,20 & 0,20 & 0,20 & 0,20 \\
\hline Suplemento mineral ${ }^{2}$ (Mineral mix) & 0,20 & 0,20 & 0,20 & 0,20 & 0,20 & 0,20 & 0,20 & 0,20 \\
\hline Tylan S 100 & 0,10 & 0,10 & 0,10 & 0,10 & 0,06 & 0,06 & 0,06 & 0,06 \\
\hline Total & 100 & 100 & 100 & 100 & 100 & 100 & 100 & 100 \\
\hline
\end{tabular}

${ }^{1}$ Suplemento vitamínico para suínos (Vitamin mix). Quantidade por quilograma do produto (amount/kg): Ác. fólico (Folic acid) 167,0 mg, Vit. A 2.330.000 UI, BHT 32.700,0 mg, Selênio (Selenium) 66,7 mg, Avoparcin 3.340,0 mg, Colina (Choline) 43.300,0 mg, Ac. pantotênico (Pantothenic acid) $2.667,0 \mathrm{mg}$, Ác. nicotínico (Nicotinic acid) $5.567,0 \mathrm{mg}$, Vit. $\mathrm{B}_{12} 66.700,0 \mathrm{mcg}$, Vit. $\mathrm{B}_{6} 667,0 \mathrm{mg}$, Vit. $\mathrm{B}_{2} 1.000,0 \mathrm{mg}$, Vit. B $234,0 \mathrm{mg}$, Vit. $K_{3} 667,0 \mathrm{mg}$, Vit. E 5.000,0 UI, Vit. $\mathrm{D}_{3} 833.000$ UI, Biotina (Biotin) 25,0 mg.

2 Suplemento mineral para suínos (Mineral mix). Quantidade por quilograma do produto (amount/kg): Cobalto (Cobalt) $500,0 \mathrm{mg}$, Cobre (Copper) $87.500,0 \mathrm{mg}$, Zinco (Zinc) 50.000,0 mg, Ferro (Iron) 50.000,0 mg, Manganês (Manganese) 20.000,0 mg, lodo (Iodine) 750,0 mg.

Tabela 4 - Composição química, valores energéticos e custo das rações experimentais fornecidas aos suínos, nas fases de crescimento e terminação ${ }^{1}$

Table 4 - Chemical composition and energy values of the experimental diets fed growing - finishing pigs

\begin{tabular}{|c|c|c|c|c|c|c|c|c|}
\hline \multirow{3}{*}{$\begin{array}{l}\text { Itens } \\
\text { Item }\end{array}$} & \multicolumn{8}{|c|}{$\begin{array}{c}\text { Níveis de inclusão de FGMD , \% } \\
\text { DCGM inclusion levels }\end{array}$} \\
\hline & \multicolumn{4}{|c|}{ Crescimento (Growing) } & \multicolumn{4}{|c|}{ Terminação(Finishing) } \\
\hline & 0 & 15 & 30 & 45 & 0 & 15 & 30 & 45 \\
\hline Energia digestível (Digestible energy), $\mathrm{kcal} / \mathrm{kg}$ & 3.331 & 3.320 & 3.317 & 3.314 & 3.378 & 3.327 & 3.313 & 3.310 \\
\hline Proteína bruta (Crude protein), \% & 17,01 & 17,07 & 17,06 & 17,06 & 15,18 & 15,17 & 15,16 & 15,15 \\
\hline Lisina (Lysine), \% & 0,82 & 0,82 & 0,81 & 0,81 & 0,70 & 0,69 & 0,68 & 0,67 \\
\hline Cálcio (Calcium), \% & 0,61 & 0,60 & 0,60 & 0,60 & 0,50 & 0,50 & 0,50 & 0,50 \\
\hline Fósforo total (Total phosphorus), \% & 0,52 & 0,52 & 0,52 & 0,51 & 0,43 & 0,43 & 0,43 & 0,43 \\
\hline Custo (Cost), R \$/kg & 0,252 & 0,248 & 0,251 & 0,254 & 0,239 & 0,235 & 0,236 & 0,239 \\
\hline
\end{tabular}

${ }_{1}^{1}$ Valores calculados com base nos dados apresentados nas Tabelas 2 e 3.

1 Values obtained from Tables 2 and 3.

\section{Experimento 2 (Desempenho)}

Os animais foram alojados em um galpão prémoldado, subdividido em 16 baias, com dois animais por unidade experimental. Cada baia continha um bebedouro tipo chupeta, um comedouro semi-automático com duas divisões e piso com lâmina d'água. Foram utilizados 32 suínos mestiços (Landrace $\mathrm{x}$ Large White x Duroc), sendo 16 fêmeas e 16 machos castrados, com peso médio inicial de $31,9 \pm 3,61 \mathrm{~kg}$, na fase de crescimento e $54,8 \pm 5,02 \mathrm{~kg}$, na fase de terminação.
A composição química, os valores energéticos e preço do FGMD e de alguns alimentos utilizados na elaboração das rações encontram-se na Tabela 2.

Os tratamentos consistiram de rações, contendo quatro níveis $(0,15,30$ e 45\%) de inclusão de FGMD, em rações formuladas à base de milho e farelo de soja (Tabela 3).

As rações foram elaboradas para atender às exigências (Tabela 4), sugeridas pelo NRC (1998). As rações e a água foram fornecidas à vontade, do início ao término do experimento. 
Os animais foram pesados no início e no final de cada fase (crescimento e terminação), sendo também anotado o consumo de ração de cada período.

Ao final da fase de terminação, foi determinada a espessura de toucinho e profundidade de lombo, em todos os suínos, por intermédio de aparelhos de ultra-som.

Posteriormente ao abate dos suínos, três por tratamento, foi efetuada a avaliação das carcaças através do Método Brasileiro de Classificação de Carcaças - MBCC (ABCS, 1973).

Para verificar a viabilidade econômica da inclusão do FGMD na ração, determinou-se o custo médio em ração por quilograma de peso vivo durante o período experimental, conforme Bellaver et al. (1985).

Também foram calculados o Índice de Eficiência Econômica (IEE) e o Índice de Custo Médio (IC), propostos por Barbosa et al. (1992).

Foi utilizado o delineamento experimental de blocos ao acaso, com quatro tratamentos e quatro repetições, com dois animais por unidade experimental (UE). Os blocos e as EU foram formados, de acordo com o peso e o sexo dos suínos.

As variáveis ganho diário de peso, consumo diário de ração, conversão alimentar, características de carcaça e o IEE, foram submetidas à análise de variância e regressão polinomial, utilizando-se o seguinte modelo estatístico:

$$
Y i j=m+N i+B j+e i j
$$

em que: $Y i j=$ variáveis observadas; $\mathrm{m}=$ média geral; $\mathrm{N} i=$ efeito dos níveis de inclusão de FGMD $i(i=0$, $15,30,45 \%)$; $\mathrm{B} j=$ efeito do bloco $j(j=1,2,3$ e 4); E $i j$ = erro aleatório associado a cada observação.

Para as variáveis de características de carcaça (Tabela 9), o peso de abate foi considerado como covariável.

Para a determinação do nível ótimo de inclusão do FGMD foi utilizado o modelo quadrático.

\section{Resultados e Discussão}

\section{Experimento 1 (Ensaio de digestibilidade)}

Os coeficientes de digestibilidade da matéria seca (CDMS), da energia bruta (CDEB), da proteína bruta (CDPB), o coeficiente de metabolização da energia bruta (CMEB) e os valores de EB, ED e EM do FGMD estão apresentados na Tabela 5.

Os valores de composição química obtidos (Tabela 5) são semelhantes aos indicados por Butolo
Tabela 5 - Composição química, coeficientes de digestibilidade (CD) da matéria seca (CDMS), da energia bruta (CDEB), da proteína bruta (CDPB) e coeficiente de metabolização da energia bruta (CMEB) e valores energéticos do farelo de germe de milho desengordurado (FGMD)

Table 5 - Chemical composition, digestibility coefficient $(D C)$ of dry mater (DCDM), gross energy (DCGE), crude protein (DCCP) and metabolizing coefficients of crude energy (MCCE) and energetic values of defatted corn germ meal (DCGM)

\begin{tabular}{lc}
\hline Itens & $\begin{array}{c}\text { Valores }(\%) \\
\text { Values }\end{array}$ \\
\hline Matéria seca (Dry matter), \% & 91,14 \\
Proteína bruta (Crude protein), \% & 10,20 \\
Extrato etéreo (Crude fat), \% & 1,27 \\
Matéria mineral (Ash), \% & 4,53 \\
CDMS (DCDM) & 45,97 \\
CDEB (DCCE) & 80,98 \\
CDPB (DCCP) & 51,15 \\
CMEB $(M C C E)$ & 78,04 \\
Energia bruta (Crude energy), kcal/kg & 3.779 \\
Energia digestível (Digestible energy), kcal/kg & 3.060 \\
Energia metabolizável, kcal/kg & 2.949 \\
Metabolizable energy & \\
\hline
\end{tabular}

et al. (2000) que encontraram: $88,46 \%$ de MS, $10,75 \%$ de $\mathrm{PB}, 3,49 \%$ de $\mathrm{FB}, 1,23 \%$ de EE, $0,26 \%$ de cálcio e $0,58 \%$ de fósforo total.

$\mathrm{O}$ valor de $3.060 \mathrm{kcal}$ de ED/kg para o FGMD (Tabela 3), determinado no presente experimento, é cerca de $88 \%$ do valor de $3.460 \mathrm{kcal}$ de $\mathrm{ED} / \mathrm{kg}$ do milho grão(EMBRAPA, 1991). Por outro lado, Butolo et al. (2000), trabalhando com aves, mostra que o valor de $2.310 \mathrm{kcal}$ de EM/kg do FGMD é cerca de $68 \%$ do valor de $3.390 \mathrm{kcal}$ de EM/kg do milho grão indicado pela EMBRAPA (1991).

O coeficiente de digestibilidade da proteína do FGMD $(51,2 \%)$ é bem inferior ao valor $(86,5 \%)$ indicado pela EMBRAPA (1991) para o milho grão integral. Resultados semelhantes são obtidos quando a comparação é feita com os dados apresentados por Rostagno et al., (2000).

\section{Experimento 2 (Desempenho)}

Na Tabela 6, são apresentados os resultados de consumo diário de ração (CDR), ganho diário de peso (GDP) e conversão alimentar (CA) média, na fase de crescimento e terminação.

Na fase de crescimento (Tabela 6), observou-se que a inclusão de níveis crescentes de FGMD não 
influenciou $(\mathrm{P}>0,05)$ o $\mathrm{CDR}$, nem a CA. Por outro lado, o GDP apresentou redução linear $(\mathrm{P}=0,0105)$, com a inclusão de níveis crescentes de FGMD. O CDR foi cerca de $8 \%$ menor, em termos numéricos ( $\mathrm{P}>0,05)$, para os tratamentos em que o FGMD estava presente. A ausência de significância estatística pode ter sido em função do elevado CV $(12,07 \%)$.

Estes resultados mostram que o FGMD, avaliado nesta pesquisa, não apresentou o problema de baixa palatabilidade indicado por Lassiter \& Edwards (1982) e Trindade Neto et al. (1995). Por outro lado, concordam com Freitas (1998) que afirma ser o germe de milho um produto de boa palatabilidade. Estes resultados conflitantes podem ser explicados pelos diferentes métodos de industrialização do milho para a obtenção do FGMD.
A inclusão de níveis crescentes de FGMD, na fase de terminação, apresentou efeito quadrático $(\mathrm{P}=0,0205)$ sobre o $\mathrm{CDR}(\mathrm{y}=3,01863-0,02548 \mathrm{x}+$ $\left.0,00055 \mathrm{x}^{2}\right)$, tendo como valor mais baixo o nível de $23,1 \%$ de FGMD. Estes resultados diferem dos obtidos na fase de crescimento, onde a inclusão do FGMD não influenciou o CDR.

$\mathrm{O}$ GDP $(\mathrm{P}=0,0266)$ e a $\mathrm{CA}(\mathrm{P}=0,0260)$ pioraram de forma linear com a inclusão de FGMD. Esta redução linear do GDP é semelhante à obtida na fase de crescimento. Entretanto, a CA apresentou comportamento diferente em relação à fase de crescimento, a qual foi semelhante para os diferentes níveis de FGMD.

$\mathrm{Na}$ Tabela 7, são apresentados os resultados de ganho diário de peso, consumo diário de ração e conversão alimentar na fase de crescimento-terminação.

Tabela 6 - Consumo diário de ração (CDR), ganho diário de peso (GDP) e conversão alimentar (CA) de suínos na fase de crescimento e terminação, alimentados com rações, contendo níveis crescentes de farelo de germe de milho desengordurado (FGMD)

Table 6 - Daily feed intake (DFI), daily weight gain (DWG) and feed:gain ratio (F:G) of growing and finishing pigs fed diets with increasing levels of defatted corn germ meal (DCGM)

\begin{tabular}{|c|c|c|c|c|c|}
\hline \multirow[t]{2}{*}{$\begin{array}{l}\text { Itens } \\
\text { Item }\end{array}$} & \multicolumn{4}{|c|}{$\begin{array}{l}\text { Níveis de inclusão de FGMD, \% } \\
\text { DCGM inclusion levels, \% }\end{array}$} & \multirow[t]{2}{*}{$\mathrm{CV}(\%)$} \\
\hline & 0 & 15 & 30 & 45 & \\
\hline \multicolumn{6}{|l|}{ Fase de crescimento $(31,9-54,8 \mathrm{~kg})$} \\
\hline $\begin{array}{l}\text { Peso vivo inicial (Initial live weight), } \mathrm{kg} \\
\text { Consumo diário de ração (Feed intake), } \mathrm{kg} \\
\text { Ganho diário de peso (Weight gain), } \mathrm{kg} \text { a } \\
\text { Conversão alimentar (Feed: gain ratio) }\end{array}$ & $\begin{array}{l}32,03 \\
2,323 \\
0,928 \\
2,503\end{array}$ & $\begin{array}{l}31,74 \\
2,134 \\
0,923 \\
2,313\end{array}$ & $\begin{array}{l}31,71 \\
2,143 \\
0,859 \\
2,487\end{array}$ & $\begin{array}{l}32,03 \\
2,134 \\
0,813 \\
2,611\end{array}$ & $\begin{array}{c}- \\
12,07 \\
6,84 \\
8,77\end{array}$ \\
\hline \multicolumn{6}{|l|}{ Fase de terminação $(54,8-79,5 \mathrm{~kg})$} \\
\hline $\begin{array}{l}\text { Peso vivo inicial (Initial live weight), } \mathrm{kg} \\
\text { Consumo diário de ração (Feed intake), } \mathrm{kg} \text { b } \\
\text { Ganho diário de peso (Weight gain), } \mathrm{kg} \mathrm{c} \\
\text { Conversão alimentar (Feed: gain ratio) } \mathrm{d}\end{array}$ & $\begin{array}{l}56,16 \\
3,038 \\
0,980 \\
3,114\end{array}$ & $\begin{array}{l}55,74 \\
2,810 \\
0,880 \\
3,194\end{array}$ & $\begin{array}{l}54,06 \\
2,707 \\
0,833 \\
3,271\end{array}$ & $\begin{array}{l}53,18 \\
2,967 \\
0,851 \\
3,478\end{array}$ & $\begin{array}{l}- \\
6,38 \\
8,14 \\
7,21\end{array}$ \\
\hline
\end{tabular}

a Efeito linear $(P=0,0105)$ (Linear effect $[P=0.0105]) ;{ }^{b}$ Efeito quadrático (Quadratic effect) $(P=0,0205){ }^{\circ}{ }^{c}$ Efeito linear (Linear effect) $(P=0,0266)$, d Efeito linear (Linear effect) $(P=0,0260)$.

Tabela 7 - Consumo diário de ração (CDR), ganho diário de peso (GDP) e conversão alimentar (CA) de suínos na fase total (crescimento - terminação), alimentados com rações, contendo níveis crescentes de farelo de germe de milho desengordurado (FGMD)

Table 7 - Daily feed intake (DFI), daily weight gain (DWG) and feed:gain ratio (F:G) of growing-finishing pigs fed diets with increasing levels of defatted corn germ meal (DCGM)

\begin{tabular}{lccccc}
\hline Itens & \multicolumn{3}{c}{ Níveis de inclusão de FGMD, \% } & \multicolumn{2}{c}{ CV (\%) } \\
\cline { 2 - 5 } & \multicolumn{3}{c}{ DCGM inclusion levels, \% } & \\
\cline { 2 - 5 } & 0 & 15 & 30 & 45 & \\
\hline Consumo diário de ração (Feed intake), $\mathrm{kg}$ & 2,667 & 2,459 & 2,415 & 2,535 & 8,65 \\
Ganho diário de peso (Weight gain), kg a & 0,953 & 0,902 & 0,847 & 0,832 & 5,59 \\
Conversão alimentar (Feed:gain ratio) & 2,797 & 2,738 & 2,864 & 3,029 & 7,15 \\
\hline
\end{tabular}

a Efeito linear (Linear effect) $(\mathrm{P}=0,0025)$.

R. Bras. Zootec., v.31, n.6, p.2238-2246, 2002 
Quando se considerou o período total (crescimento-terminação), observou-se redução linear $(\mathrm{P}=0,0025)$ do GDP (Tabela 7), com a inclusão crescente de FGMD. Esta resposta foi semelhante à das fases de crescimento e terminação. Por outro lado, diferente da fase de terminação, porém, semelhante à fase de crescimento, não houve efeito $(\mathrm{P}>0,05)$ dos níveis de FGMD sobre as variáveis CDR e CA.

A CA, embora não tenha sido influenciada $(\mathrm{P}=0,0942)$, mostrou uma diferença numérica importante $(2,4$ e $8,29 \%)$, respectivamente para os níveis 30 e 45\%, em comparação ao nível 0\% (sem FGMD). Este comportamento (Tabela 7) foi fortemente influenciado pela piora linear na CA, observada na fase de terminação (Tabela 6), porém, não suficiente para mostrar significância no período total.

Apesar de o FGMD passar por um processo de industrialização semelhante ao do glúten de milho, não foi verificado efeito de redução do consumo de ração (Tabela 7) no período total, como encontrado por Trindade Neto et al. (1995), em trabalho com glúten de milho.

Estes resultados de desempenho dos suínos discordam por um lado de Lassiter \& Edwards (1982), os quais mencionam que o FGMD possui baixa palatabilidade, por outro lado, concordam com os mesmos autores, quando estes sugerem que a inclusão do FGMD nas rações de suínos deve ser limitada.

A piora na CA, observada na fase de terminação, pode indicar que pode ter havido uma superestimativa do valor energético do FGMD ou mesmo ser um reflexo da baixa digestibilidade da proteína, que foi de $51,15 \%$ (Tabela 5), o que refletiu na redução do ganho de peso, tanto nas fases de crescimento e terminação (Tabela 6), como na fase total (Tabela 7).

Tabela 8 - Características de carcaça medidas em suínos vivos ao final da fase de terminação, alimentados com níveis crescentes de FGMD

Table 8 - Finishing pigs carcasses traits fed on increasing levels of defatted corn germ meal (DCGM)

\begin{tabular}{|c|c|c|c|c|c|}
\hline \multirow[t]{2}{*}{$\begin{array}{l}\text { Itens } \\
\text { Item }\end{array}$} & \multicolumn{4}{|c|}{$\begin{array}{l}\text { Níveis de inclusão de FGMD, \% } \\
\text { DCGM inclusion levels, \% }\end{array}$} & \multirow[t]{2}{*}{$\mathrm{CV}(\%)$} \\
\hline & 0 & 15 & 30 & 45 & \\
\hline Peso final, $\mathrm{kg}$ & 83,60 & 79,99 & 77,40 & 77,01 & \\
\hline $\begin{array}{l}\text { Final weight } \\
\text { Espessura de toucinho P2 (LM), mm }{ }^{\mathrm{a}} \\
\text { Backfat thickness }\end{array}$ & 17,5 & 15,37 & 14,87 & 13,62 & 15,03 \\
\hline $\begin{array}{l}\text { Espessura de toucinho P3 (LM), mm } \\
\text { Backfat thickness }\end{array}$ & 19,12 & 16,75 & 15,75 & 15,75 & 19,88 \\
\hline $\begin{array}{l}\text { Espessura de toucinho P2 (SG), mm } \\
\text { Backfat thickness }\end{array}$ & 16,62 & 14,50 & 13,75 & 13,12 & 14,47 \\
\hline $\begin{array}{l}\text { Profundidade de lombo (SG), mm } \\
\text { Loin depth }\end{array}$ & 50,25 & 50,00 & 46,62 & 49,25 & 14,87 \\
\hline
\end{tabular}

$\mathrm{LM}=$ medida feita com aparelho de ultra-som RENCO Lean Meater® (measured with RENCO Lean Meaterâ ultrasound equipment); $\mathrm{SG}=$ medida feita com aparelho de ultra-som RENCO Sono Grader ${ }^{\circledR}$ (measured with RENCO Sono Grader ${ }^{\circledR}$ ultrasound equipment); ${ }^{a}$ Efeito linear (Linear effect) $(P=0,0182) ;{ }^{b}$ Efeito linear (Linear effect) $(P=0,0301)$.

Tabela 9 - Características de carcaça de suínos alimentados com níveis crescentes de FGMD, abatidos ao final do experimento

Table 9 - Pigs carcasses traits fed on increasing levels of defatted corn germ meal (DCGM) slaughtered at the end of the experiment

\begin{tabular}{|c|c|c|c|c|c|}
\hline \multirow[t]{2}{*}{$\begin{array}{l}\text { Itens } \\
\text { Item }\end{array}$} & \multicolumn{4}{|c|}{$\begin{array}{c}\text { Níveis de inclusão de FGMD, \% } \\
\text { DCGM inclusion levels, \% }\end{array}$} & \multirow[t]{2}{*}{$\mathrm{CV}(\%)$} \\
\hline & 0 & 15 & 30 & 45 & \\
\hline Peso de abate (Slaughter weight), kg & 85,97 & 83,37 & 82,00 & 80,27 & \\
\hline Peso de carcaça (Carcass weight), kg & 68,00 & 66,73 & 64,13 & 63,90 & 3,07 \\
\hline Rendimento de carcaça (Carcass yield), \% & 78,99 & 80,06 & 78,16 & 79,51 & 2,84 \\
\hline Comprimento de carcaça (Carcass length), $\mathrm{cm}$ & 93,97 & 90,23 & 93,00 & 92,40 & 2,54 \\
\hline Espessura de toucinho (Backfat thickness), $\mathrm{cm}$ & 3,19 & 3,02 & 2,77 & 2,92 & 9,97 \\
\hline Rendimento de pernil (Ham yield), \% & 31,87 & 33,09 & 32,49 & 32,09 & 2,90 \\
\hline Área de olho de lombo (Loin eye area), $\mathrm{cm}^{2}$ & 41,30 & 44,11 & 38,54 & 34,54 & 19,81 \\
\hline
\end{tabular}

R. Bras. Zootec., v.31, n.6, p.2238-2246, 2002 
Nas Tabelas 8 e 9, são apresentados os resultados da avaliação de carcaça, feitas ao final da fase de terminação.

Observou-se que a espessura de toucinho (ET) medida em suínos vivos, ao final do experimento (Tabela 8), apresentou redução linear para leitura P2 $(\mathrm{P}=0,0182)$, feita com o aparelho RENCO Lean Meaterâ e para leitura $\mathrm{P} 2(\mathrm{P}=0,0301)$, realizada com o aparelho RENCO Sono Grader ${ }^{\circledR}$. Porém, este efeito não foi observado na espessura de toucinho medida na carcaça (Tabela 9), em que apenas alguns animais foram abatidos.

A diferença de resultados entre a espessura de toucinho medidas no suíno vivo e na carcaça, pode ser em função do pequeno número (três por trata- mento) de animais abatidos por tratamento. A redução na ET na posição P2 não era esperada, já que as rações possuem níveis energéticos bastante semelhantes.

As características de carcaça (Tabela 9) avaliadas segundo o MBCC (ABCS, 1983) não foram influenciadas $(\mathrm{P}>0,05)$ pelos níveis crescentes de inclusão de FMGD nas rações. Como as rações possuem níveis energéticos bastante semelhantes, não eram esperadas alterações nas características de carcaça.

Nas Tabelas 10 e 11, é apresentada a análise econômica, com simulação de preço do FGMD de $80 \%$ do valor do milho, índice normalmente utilizado no mercado, para fase de crescimento e terminação, respectivamente.

Na simulação de preço de $80 \%$ do preço do milho

Tabela 10 - Custo médio em ração por quilograma de peso vivo ganho ( $R$ \$/kg de $P V)$, índice médio de custo e índice de eficiência econômica de suínos, na fase de crescimento, consumindo rações contendo FGMD ${ }^{1}$

Table 10 - Mean cost in diet per kilogram of live weight gain, mean cost index and economic efficiency index of growing pigs fed on increasing levels of defatted corn germ meal (DCGM)

\begin{tabular}{|c|c|c|c|c|c|}
\hline \multirow[t]{2}{*}{$\begin{array}{l}\text { Itens } \\
\text { Item }\end{array}$} & \multicolumn{4}{|c|}{$\begin{array}{c}\text { Níveis de inclusão de FGMD, \% } \\
\text { DCGM inclusion levels, \% }\end{array}$} & \multirow[t]{2}{*}{$\mathrm{CV}(\%)$} \\
\hline & 0 & 15 & 30 & 45 & \\
\hline $\begin{array}{l}\text { Custo em ração, } \mathrm{R} \$ / \mathrm{kg} \text { de } \mathrm{PV}^{2} \\
\text { Cost in diet }\end{array}$ & 0,630 & 0,567 & 0,610 & 0,640 & 8,46 \\
\hline Índice de custo médio & 111,11 & 100,00 & 107,58 & 112,87 & - \\
\hline $\begin{array}{l}\text { Índice de eficiência econômica } \\
\text { Economic efficiencyindex }\end{array}$ & 90,00 & 100,00 & 92,95 & 88,59 & - \\
\hline
\end{tabular}

${ }^{1}$ Considerando o preço do FGMD igual a $80 \%$ do preço do milho grão.

${ }^{1}$ Considering DCGM price equal to $80 \%$ of corn grain price.

$2(\mathrm{P}>0,05)$.

Tabela 11 - Custo médio em ração por quilograma de peso vivo ganho (R\$/kg de PV), índice médio de custo (IMC) e índice de eficiência econômica (IEE) de suínos na fase de terminação, consumindo rações contendo FGMD ${ }^{1}$

Table 11 - Mean cost in diet per kilogram of live weight gain, mean cost index and economic efficiency index of finishing pigs fed on increasing levels of defatted corn germ meal (DCGM) ${ }^{1}$

\begin{tabular}{|c|c|c|c|c|c|}
\hline \multirow[t]{2}{*}{$\begin{array}{l}\text { Itens } \\
\text { Item }\end{array}$} & \multicolumn{4}{|c|}{$\begin{array}{c}\text { Níveis de inclusão de FGMD, \% } \\
\text { DCGM inclusion levels, \% }\end{array}$} & \multirow[t]{2}{*}{$\mathrm{CV}(\%)$} \\
\hline & 0 & 15 & 30 & 45 & \\
\hline $\begin{array}{l}\text { Custo em ração, } \mathrm{R} \$ / \mathrm{kg} \text { de } \mathrm{PV}^{2} \\
\text { Cost in diet }{ }^{2} \\
\text { Índice de custo médio }\end{array}$ & 0,743 & 0,740 & 0,753 & 0,801 & 7,69 \\
\hline $\begin{array}{l}\text { Average cost index } \\
\text { Índice de eficiência econômica }\end{array}$ & 100,41 & 100,00 & 101,76 & 108,24 & - \\
\hline Economic efficiencyindex & 99,60 & 100,00 & 98,27 & 92,38 & - \\
\hline
\end{tabular}

${ }^{1}$ Considerando o preço do FGMD igual a $80 \%$ do preço do milho grão.

1 Considering DCGM price equal to $80 \%$ of corn grain price.

$2(P>0,05)$.

R. Bras. Zootec., v.31, n.6, p.2238-2246, 2002 
para o FGMD, nas fases de crescimento e terminação, observou-se que não houve efeito $(\mathrm{P}>0,05)$ sobre o custo médio em ração por quilograma de peso vivo. Entretanto, o nível de 15\% de FGMD apresentou resultados mais econômicos em ambas as fases, de acordo com o ICM e IEE. Estes resultados sugerem que o FGMD com preço de $80 \%$ ou menor, em relação ao preço do milho, torna-se viável economicamente, tanto na fase de crescimento, quanto na fase de terminação de suínos.

Os resultados promissores, mas não conclusivos, sugerem que mais estudos sejam feitos, objetivando melhor conhecer o valor nutricional do FGMD para alimentação de suínos. Ênfase deve ser dada no estudo do conteúdo de fibra e balanço de aminoácidos do FGMD.

\section{Conclusões}

O coeficiente de digestibilidade da energia, coeficiente de metabolização, ED e EM do FGMD é: $80,98 \%, 78,04 \%, 3.060 \mathrm{kcal} / \mathrm{kg}$ e $2.949 \mathrm{kcal} / \mathrm{kg}$, respectivamente.

A inclusão de níveis crescentes de FGMD nas rações de suínos, na fase de crescimento e terminação, leva à piora no desempenho dos animais, reduz a espessura de toucinho e não influencia a profundidade do lombo, medidas no animal vivo.

Se o preço do FGMD for $80 \%$ do preço do milho, o nível de $15 \%$ de inclusão do FGMD é o mais econômico, tanto para a fase de crescimento, quanto para a fase de terminação.

\section{Agradecimento}

À KOWALSKY Alimentos Ltda., pelo fornecimento do farelo de germe de milho desengordurado, bem como pelo apoio à condução do experimento.

\section{Literatura Citada}

ANDRIGUETTO, J.M.; PERLY, L.; MINARDI, I. et al. Nutrição animal. Curitiba: Universidade Federal do Paraná, 1982. 395 p. (Volume 1).

ASSOCIAÇÃO BRASILEIRA DE CRIADORES DE SUÍNOS - ABCS. Método Brasileiro de Classificação de Carcaça. Estrela, RS: 1973. 17p.

BARBOSA, H.P.; FIALHO, E.T.; FERREIRA, A.S. et al. Triguilho para suínos nas fases inicial de crescimento, crescimento e terminação. Revista da Sociedade Brasileira de Zootecnia, v.21, n.5, p.27-37, 1992.
BELLAVER, C.; FIALHO, E.T.; PROTAS, J.F.S. et al. Radícula de malte na alimentação de suínos em crescimento e terminação. Pesquisa Agropecuária. Brasileira, v.20, n.8, p.69-74, 1985.

BUTOLO, E.A.F.; NOBRE, P.T.C.; LIMA, I.A.V. et al. Determinação do valor energético e nutritivo do gérmen de milho desengordurado para frangos de corte. http://www.supremais.com.br/08.htm (20/07/2000).

EMPRESA BRASILEIRA DE PESQUISA AGROPECUÁRIA - EMBRAPA/CNPSA. Tabelas de composição química e valores energéticos de alimentos para suínos e aves. 3.ed. Concórdia, SC: 1991. 97p.

FREITAS, R.M. Fontes alternativas para o milho. In: SEMINÁRIO NUTRON DE SUINOCULTURA, 2., 1998, Campinas, Anais... Local: NUTRON. 1988. p.15-24.

GIROTTO, A.F.; SANTOS FILHO, J.J. Custo de produção de suínos. Concórdia: EMBRAPA/CNPSA, 2000. 36p (Documentos, 62).

TRINDADE NETO, M.A.; LIMA, J.A.F.; FIALHO, E.T. et al. Farelo de glúten de milho (FMG) para suínos em crescimento e terminação (desempenho). Revista da Sociedade Brasileira de Zootecnia, v.24, n.1, p.108-116, 1995.

LASSITER, J.W.; EDWARDS Jr.; H.M. Animal nutrition. Virginia: Reston Publishing Company, 1982. p.339-340.

MATERSON, L.D.; POTTER, L.M.; STUTZ, M.W. et al. The metabolizable energy of feed ingredients for chickens. Research Report, v.7, n.1, p.11-14, 1965.

MOREIRA, I.; ROSTAGNO, H.S.; COELHO, D.T. et al. Determinação dos coeficientes de digestibilidade, valores energéticos e índices de controle de qualidade do milho e soja integral processados a calor. Revista da Sociedade Brasileira de Zootecnia, v.23, n 6, p.916-929. 1994.

NATIONAL RESEARCH COUNCIL - NRC. Nutrient requirements of swine. 10.ed. Washington, D.C.: 1998. 189p.

PEKAS, J.C. Versatile swine laboratory apparatus for physiologic and metabolic studies. Journal of Animal Science, v.27, n.5, p.1303-1306, 1968.

TRINDADE NETO, M.A.; LIMA, J.A.F.; FIALHO, E.T., et al. Farelo de glúten de milho (FMG) para suínos em crescimento e terminação (desempenho). Revista da Sociedade Brasileira de Zootecnia, v.24, n.1, p.108-116. 1995.

PATIENCE, J.F.; THACKER, P.A.; LANGE, C.F.M. Swine nutrition guide. 2.ed. Saskatoon: Prairie Swine Centre, 1995. 274p.

ROSTAGNO, H.S.; ALBINO, L.F.T.; DONZELE, J.L. et al. Tabelas brasileiras para aves e suínos: composição de alimentos e exigências nutricionais. Viçosa, MG: Universidade Federal de Viçosa, 2000. 141p.

SIMMONS, N.O. Tecnología de la fabricación de piensos. Zaragoza: Acribia, 1979.410p.

OHIOCORN-THE OHIO CORN GROWERS ASSOCIATION. The many uses of corn, 4-Jan-2000a, http:// www.ohiocorn.org/usage/uses.htm (16/06/2000).

OHIOCORN-THE OHIO CORN GROWERS ASSOCIATION. What's in a kernel of corn?, 4-Jan-2000b, http:// www.204.240.36.22:80/./about/kernel.htm (04/09/2000).

Recebido em: 10/12/01 Aceito em: 08/08/02 